\title{
Hazards of Living on the Edge of Water: The Case of Minnesota Point, Duluth, Minnesota
}

\author{
Harun Rasid ${ }^{1}$ and James Hufferd ${ }^{2}$
}

Based on a systematic sample survey among the residents of Minnesota Point, a fresh-water spit/baymouth bar on the southwest shore of Lake Superior, this study tests a number of hypotheses related to the perceived causes of lake level fluctuation and shore property hazards. The study found that, despite significant differences in property setting and the nature of flood and erosion hazards between the lakeside and the bayside of the spit, the majority of the respondents perceived that their property hazards were induced primarily by the manipulation of lake levels by the International Joint Commission (IJC). Consequently, one in every two respondents would like to lower the lake level by amounts ranging from $30 \mathrm{~cm}$ to more than $1 \mathrm{~m}$. The study points out the physical limitations of controlling water levels and recommends that greater attention should be given to shoreline management, which could proivde guidelines for protecting existing coastal structures and for developing minimum standards for future encroachment of the remaining unused sections of the shoreline.

KEY WORDS: property hazards; building setback; shore protection measures; manipulation of lake levels; shoreline management.

\section{INTRODUCTION}

For decades, industrial societies have viewed natural phenomena that impinge upon their lives as hazards to their well-being. The traditional response has been to try to eliminate the hazards with the technology at hand (Rowntree, 1974). Thus, dams and levees have been built to control river

\footnotetext{
${ }^{1}$ Associate Professor, Department of Geography, Lakehead University, Thunder Bay, Ontario, Canada P7B 5E1

${ }^{2}$ Formerly of the Department of Geography, University of Minnesota, Duluth, Minnesota 55812.
} 


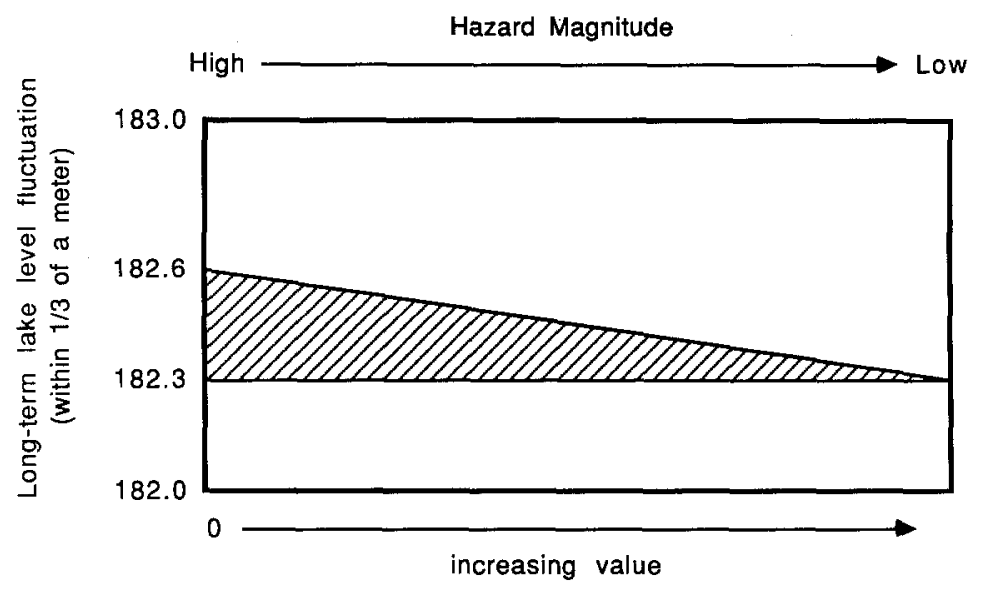

Distance from the edge of water $\mathbf{x}$ elevation

Fig. 1. A postulated relationship between lake level fluctuations and the magnitude of property hazards on Minnesota Point.

floods and groins and sea walls have been designed to protect water's edge from coastal erosion and flooding. One of the outcomes of this technological fix has been growing settlement of hazard-prone areas, with an implicit assumption by the occupants that science and technology can readily be used to deal with every problem (Clawson, 1972). Consequently, it has become increasingly difficult for modern Western society, particularly for those living in a hazardous but otherwise attractive environment, to appreciate the fact that man cannot control all aspects of nature. They are so offended by the notion that phenomena such as high lake levels or large river floods due to unpredictably high levels of precipitation are beyond human control, that they must offer explanations blaming other humans for these undesirable outcomes. The popular misconception about the causes of recent high water levels in the Great Lakes is an example. According to this explanation, the regulation of lake levels by the International Joint Commission (IJC) is postulated as the main cause of lake level fluctuation and very little attention is given to more important natural causes. Such an attitude is pervasive among the coastal residents on the Great Lakes who tend to absolve themselves of any responsibility for occupying the hazardous edge of water by resorting to this type of explanation. The central objective of this paper is to test this hypothesis by using a case study on Minnesota Point, a low lying costal settlement on a spit, located on the southwest shore of Lake Superior, which is susceptible to coastal flooding and erosion hazards due to even minor fluctuations in lake levels (Fig. 1). Data from a questionnaire survey form the basis of testing this hypothesis and a number of other related assumptions. Alternative explanations of the main causes of lake level fluctuation have 
been reviewed and implications of this fluctuation for shoreline management are discussed at some length.

\section{ENVIRONMENTAL SETTING}

Minnesota Point, a 12-km log sandspit that separates Duluth Harbor and Superior Bay from the main water body of Lake Superior, is the exposed half of a continuous baymouth bar that extends from the shoreline of the City of Duluth to the south shore of Lake Superior in Wisconsin (Fig. 2). The middle portion of the bar is submerged and separates Minnesota Point

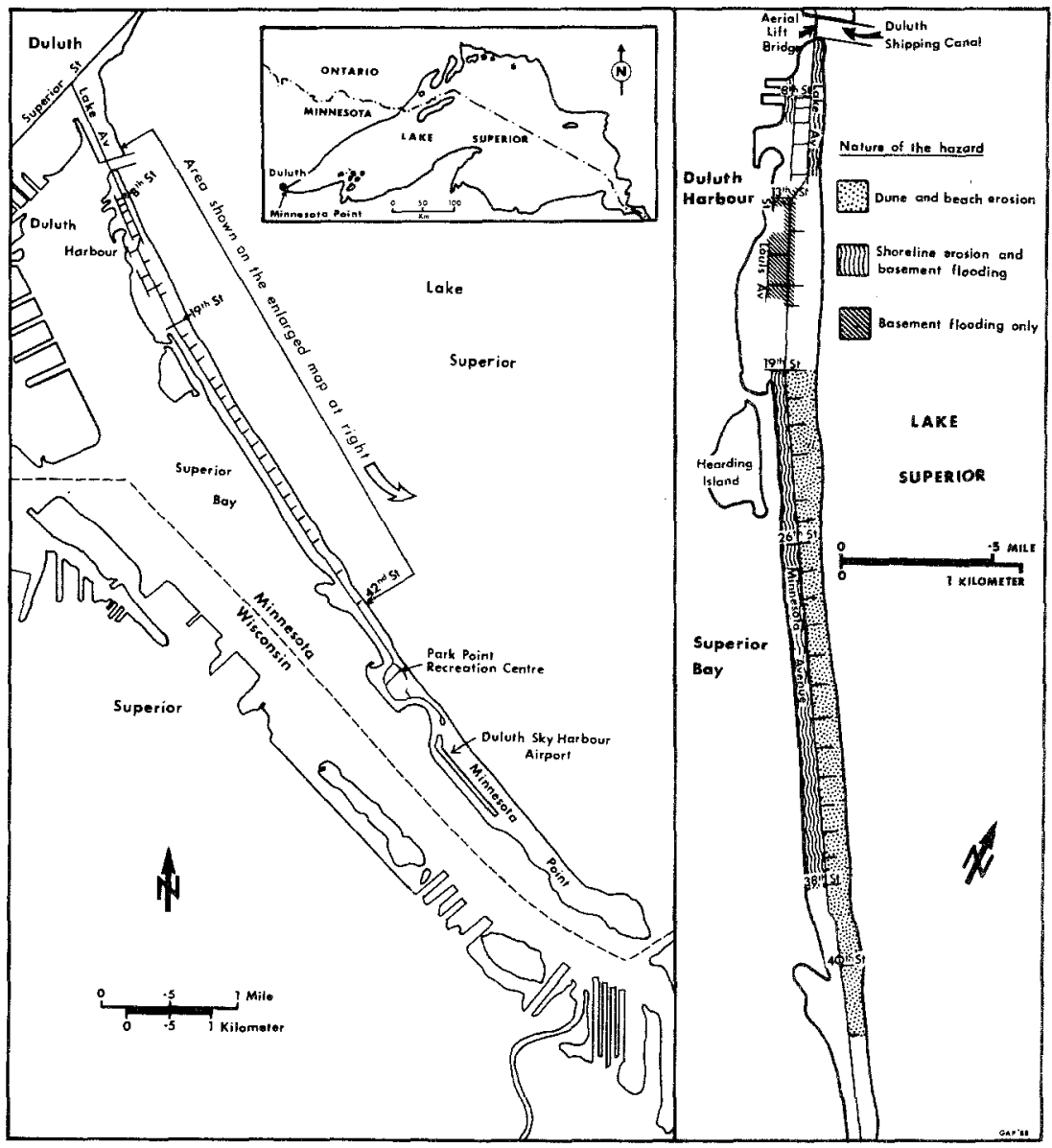

Fig. 2. Location of Minnesota Point on the southwest shore of Lake Superior. The inset map (right) shows the geographical distribution of different types of property hazards during the 1985-1986 high water period. 
from the second spit, Wisconsin Point. The geologic formation of this freshwater baymouth bar is attributed primarily to littoral drift of sandy materials (mostly from the south shore) and secondarily to the outflow of the St. Louis and Nemadji Rivers (Loy, 1963). Two major engineering structures have been built through the bar. The Superior Entry concrete breakwaters were built in 1869. The Duluth Shipping Canal was excavated in 1871 and consists of two concrete piers/groins, $600-\mathrm{m}$ long and $90-\mathrm{m}$ wide (Corps of Engineers, 1976).

The bulk of Minnesota Point is composed of sandy materials, but the shoreline along the bayside has been modified considerably by artifical fill (dredged) materials. The bayside is protected from strong wave action by its restricted wind-wave fetches (less than $10 \mathrm{~km}$ ). In contrast, the shoreline along the lakeside consists of natural beaches and dunes which are exposed to long fetches, ranging from $300-600 \mathrm{~km}$. Winds from the northeasterly direction generate high waves along these fetches. Significant wave heights in open water may range between 5-6 m (Resio and Vincent, 1978). No such estimates are available for the bayside; but computations by the present authors, using wave charts and wind data, indicate wave heights of much lower magnitudes (only about $1 / 3$ the size of those on the lakeside). Although strong wave action along the lakeside may cause temporary loss of beach materials, on a long-term basis these beaches are characterized by equilibrium profiles with slope angles ranging between 5-7 degrees (Loy, 1963; Corps of Engineers, 1976). Dune formations, ranging in elevation from 3-10 m, are sparsely vegetated and vulnerable to wave attacks during periods of high lake levels when the beaches are submerged.

The levels of Lake Superior experience short-term (hourly), seasonal and long-term fluctuations. Spectaular changes in levels result from shortterm oscillations of lake surfaces induced by wind set-up and seiche, which may raise or lower the lake level by up to $1 \mathrm{~m}$ within a period of a few hours (Hough, 1958). The low-lying coastal areas of the Minnesota Point are capable of absorbing the effects of such short-term oscillations during periods of normal lake levels (at $\sim 183.2 \mathrm{~m}$ ). However, if such oscillations are superimposed on an additional rise of even one-third of a meter, significant flood and erosion hazards are experienced along the shoreline (Fig. 1). The seasonal regimes are more predictable; the lake normally fluctuates about $30 \mathrm{~cm}$ annually, being lowest before the snow melts in the spring and highest in September.

In constrast to seasonal regimes, long-term fluctuations appear to have an irregular cycle. The 128-year lowest mean annual level was recorded in 1925-1926 at $182.9 \mathrm{~m}$. Following that, at least three periods of high lake levels were experienced: in 1950-1951, 1972-1973, and 1985-1986 (Fig. 3). A second period of low levels occurred during the 1960's, when major residen- 


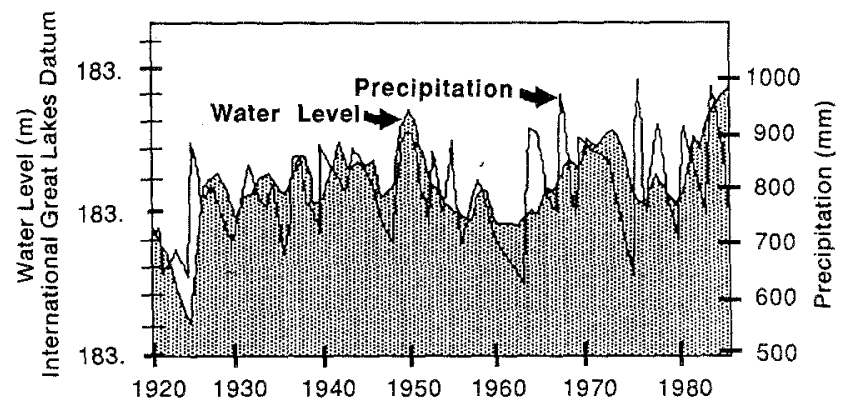

Fig. 3. Lake Superior water level and precipitation, 1920-1986.

tial expansion took place on the Minnesota Point. The lake levels have been rising since 1960's, leading to record high water levels for 12 consecutive months in 1985-1986 (Fig. 3). Such high water levels are caused when inputs of precipitation, ground water, surface runoff, and streamflow exceed the outputs of evaporation and outflow from the lake. The lake levels are also dependent upon human regulation systems; the outflow is regulated through the Sault Ste. Marie locks by the International Joint Commission (IJC), whereas two diversion structures (The Ogoki River and Long Lac River) divert about $140 \mathrm{~m}^{3} / \mathrm{s}$ of steamflow from the Hudson Bay basin into Lake Superior (Yee and Cuthbert, 1985). Working under an agreement known as Plan 1977 , the IJC strives to keep Lake Superior's monthly mean level between 182.38-183.48 m, while balancing water levels between Lake Superior and Lakes Michigan, Huron, and Erie. However, the lake's natural water balance overrides the effects of human regulation systems. For example, the 1985-1986 high water levels resulted from a prolonged regime of abovenormal precipitation, higher runoff, and lower evaporation (Quinn, 1987).

\section{QUESTIONNAIRE SURVEY}

The first comprehensive damage survey on the Minnesota Point was carried out by the U.S. Army Corps of Engineers immediately following the 1972-1973 high water period (Corps of Engineers, 1976). Although this survey provided estimates of relative proportions of residential and nonresidential parcels of properties (as presented in Table I), the total number of houses were not reported. In a more recent submission to the U.S. House of Representatives, the City of Duluth estimated that there were 490 homes, apartments, and other institutions on Minnesota Point (Carson, 1987). The present authors counted $\mathbf{4 3 2}$ single- and double-family residential structures between the Duluth Shipping Canal and 42nd St. (Fig. 2). A systematic sam- 
Table I. Types of Properties on Minnesota Point, 1973-1974 ${ }^{a}$

\begin{tabular}{lcc}
\hline \multicolumn{1}{c}{ Types of ownership } & Parcels of ownerships \\
\hline Residential & $197(66 \%)$ \\
$\begin{array}{l}\text { Non-residential } \\
\text { Breakdown of non-residential properties }\end{array}$ & $103 \quad(34 \%)$ \\
$\quad$ City of Duluth & 39 \\
(Park Point Recreation Center, & \multicolumn{2}{|c}{} \\
Municipal airport, firehall, etc.) & 37 \\
State of Minnesota & 15 \\
Federal Government & \multicolumn{2}{|c}{} \\
(U.S. Coast Guard, U.S. Naval Station, & 2 \\
U.S. Army Corps of Engineers, etc.) & 10 \\
ST. Louis County & \multicolumn{2}{|c}{} \\
Unclassified &
\end{tabular}

${ }^{a}$ Source: COE, 1976.

ple was attempted by selecting every alternate household that had a visible address and a mailbox. The questionnaire was filled out at the site if a respondent was at home and agreed to an interview. If there was no one at home, a copy of the questionnaire was left in the mailbox with a request that it be filled out and returned by using the attached addressed and stamped envelope. In all, 250 households were visited. The response rate, expressed as the proportion of the total population, was approximately $40 \%$ (175 respondents out of 432 households; with a confidence limit of $\pm 6 \%$ at $p=0.05$ ). The geographical distribution of respondents was fairly representative of the subpopulations on the lakeside and the bayside. Thus, 94 responses on the lakeside and 81 on the bayside represent approximately $40 \%$ of the populations on each side (Table II).

Table II. Property Setting ${ }^{a}$

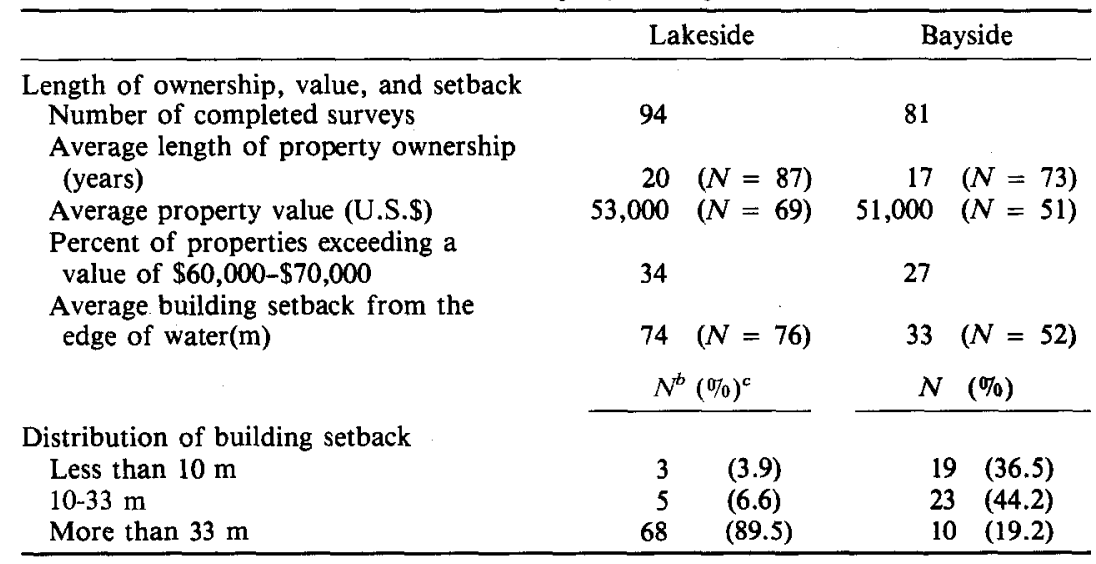

${ }^{a}$ Chi-square $=64.00, d f=2$, significant at 0.001 level.

${ }^{b} N=$ number of respondents.

$(\%)=$ Percent of respondents who reported property setback. 


\section{PROPERTY SETTING}

Residential development on the Minnesota Point was initiated at the turn of this century. The longest period of property ownership reported in this survey is 72 years. However, less than one-third of the properties $(30 \%)$ were owned for 25 years or longer and more than one-half of $(52 \%)$ were acquired during the last 15 years, i.e., following the 1972-1973 high water period. Such short-term ownerships probably indicate recent constructions as well as large turnover of hazard-prone properties and imply that more than one-half of the respondents experienced high lake levels in 1985-1986 for their first time. The length of ownership is shorter and property values are lower on the bayside than on the lakeside (Table II). Not only are the more expensive homes located on the lakeside, but most of the properties on this side are also situated on higher grounds with wider building setback. The height of the base of buildings on this side ranges between 2-3 $\mathrm{m}$ above the lake level, whereas on the bayside most of the buildings are situated within an elevation of $1-1.5 \mathrm{~m}$ above the water level.

The impact of high lake levels on a specific property is governed by a combination of two basic variables: building setback and elevation. Since the range of elevation is relatively small $(1-3 \mathrm{~m})$, the variation in building setback is the principal determinant of property hazards. The building setback for approximately $90 \%$ of the properties on the lakeside exceeds 33 $\mathrm{m}$, whereas on the bayside the setback is less than this value for about $81 \%$ of the properties. At least one-third of the buildings on the bayside $(36 \%)$ are located within $10 \mathrm{~m}$ of the edge of water. The difference of means tests as well as the chi-square tests indicate that these differences in setback are significantly related to the location of properties on either the lakeside or the bayside (Table II). Further cross-tabulations of data on setback with the frequency of flood and erosion damages also indicate a significant relationship between location and property hazards. Thus, about three-quarters of the properties on the bayside (71.6\%), all of which had a setback of less than $33 \mathrm{~m}$, experienced flood and erosion damages during the 1985-1986 high water period. On the lakeside only $40 \%$ of the properties reported such damages (Tables III and IV).

\section{FLOOD DAMAGE AND EROSION MAGNITUDE}

No attempt was made to estimate the cost of flood damage. Property owners were asked to report on the nature of flood damage. Two types of flood damage were reported: (1) flooding of basements due to a rise in the water table, and (2) direct inundation of yards and outbuildings, such as garages and storage sheds, mostly during storm wave conditions. More than 
Table III. Nature of Flood Damage During the 1985-1986 High Water Period

\begin{tabular}{|c|c|c|c|c|}
\hline & & keside & & yside \\
\hline & & $(\%)^{c}$ & & $(\%)$ \\
\hline No flood damage & 55 & $(58.5)$ & 23 & $(28.4)$ \\
\hline $\begin{array}{l}\text { Basements, yards, and outbuildings flooded } \\
\text { Yards and outbuildings flooded }\end{array}$ & 30 & (31.9) & 45 & (55.6) \\
\hline (excluding basements) & 9 & $(9.6)$ & 13 & (16) \\
\hline
\end{tabular}

${ }^{a}$ Chi-square $=15.97, d f=2$, significant at 0.001 level.

${ }^{b} N=$ number of respondents.

${ }^{c}(\%)=$ Percent of sample on each side.

three-quarters of the respondents on each side of the spit who reported flood damage indicated that they experienced both of these types of floods simultaneously. The remaining one-quarter experienced only inundation of yards and outbuildings (Table III). Thus, there was no significant difference between the lakeside and the bayside in the relative proportions of two types of flood damage. However, the overall frequency of flood damage was 1.6-1.7 times higher on the bayside than on the lakeside. The chi-square tests of association between location and the frequency of flood damage indicate that these relationships are significant at 0.001 level (Table III). Lower elevation and limited property setback are the two main causes of higher frequency of flooding on this side.

There are no published data on erosion rates for Minnesota Point. The Natural Resources Research Institute of the University of Minnesota-Duluth has recently initiated a coastal erosion measurement program for the Minnesota shore of Lake Superior by using historical aerial photographs and ground reconnaissance survey (Johnston, personal communication). Minnesota Point is included in this program, but erosion rates have not yet been determined. In the absence of actual data, property owners were asked to estimate erosion rates. The magnitude of the erosion problem is reflected in the estimated erosion rates on the lakeside and in the frequency of erosion on the bayside (Table IV). Average long-term erosion rates as well as the 1985-1986 rates were approximately 3-5 times higher on the lakeside than on the bayside. This can be attributed principally to the effect of the exposure of this side to long wind-wave fetches. The average long-term erosion rates were calculated by dividing the total amount of erosion (since property owned) by the average length of property ownership. These rates appear to be significantly lower than the 1985-1986 rates. There are at least two probable explanations for this. First, the 1985-1986 rates were probably higher than the previous rates due to the above-average duration of high lake levels. Second, people's perception of a hazard tends to be magnified with the recen- 
Table IV. Magnitude of Erosion ${ }^{\text {\# }}$

\begin{tabular}{|c|c|c|}
\hline & Lakeside & Bayside \\
\hline \multicolumn{3}{|l|}{ Estimated erosion rates } \\
\hline \multirow{2}{*}{\multicolumn{3}{|c|}{$\begin{array}{l}\text { Estimated total amount of erosion since } \\
\text { property owned (m) }\end{array}$}} \\
\hline & $(N=16)$ & $2.2 \quad(N=25)$ \\
\hline \multicolumn{3}{|l|}{$\begin{array}{l}\text { Average long-term erosion rates }(\mathrm{m} / \mathrm{y}) \\
\text { Average } 1985-1986 \text { erosion rates }\end{array}$} \\
\hline \multirow[t]{2}{*}{$(\mathrm{m} / \mathrm{y})$} & $3.14(N=16)$ & $1.1 \quad(N=30)$ \\
\hline & $N^{b}(\%)^{c}$ & $N(\%)$ \\
\hline \multicolumn{3}{|l|}{ Magnitude of 1985-1986 erosion estimates } \\
\hline No erosion & $57(60.6)$ & $23 \quad(28.4)$ \\
\hline Less than $1 \mathrm{~m}$ & $2(2.1)$ & $20 \quad(24.7)$ \\
\hline More than $1 \mathrm{~m}$ & $14 \quad(14.9)$ & $10 \quad(12.3)$ \\
\hline Erosion rates not specified & $21 \quad(22.3)$ & $28 \quad(34.6)$ \\
\hline
\end{tabular}

${ }^{a}$ Chi-square $=21.46, d f=3$, significant at 0.001 level.

${ }^{b} N=$ number of respondents.

${ }^{c}(\%)=$ Percent of sample on each side.

cy of the event (White, 1974). According to this hypothesis, it is probable that the long-term rates were underestimated and the most recent rates were exaggerated. Since it would be difficult to verify the accuracy of such data, the magnitude of recent erosion was further analyzed by using the ranges of erosion rates to examine if there was any pattern in the nature of erosion estimates on the lakeside and the bayside. These data, indeed, confirm the lakeside-bayside dichotomy; while a larger number of respondents reported erosion rates of more than $1 \mathrm{~m} / \mathrm{yr}$ on the lakeside, the frequency of overall erosion is about 1.8 times higher on the bayside. The chi-square tests indicate that these associations between location and the frequency of erosion are significant at 0.001 level (Table IV, bottom). Lower erosion rates on the bayside reflect the effects of restricted fetches and sheltered wave climates, while higher frequencies of erosion may be attributed to the physical setting of the properties (lower elevation and limited setback) that make them highly vulnerable to erosion. Also, awareness of the erosion problem might have been higher on this side due to the location of a large number of homes near the edge of water.

The lakeside-bayside dichotomy can be further examined through the geographical distribution of the nature of hazards. Although three types of hazards are illustrated in Fig. 2, the dominant problem on the lakeside is dune and beach erosion (Between 19th and 42nd Streets), whereas on the bayside the combined effects of shoreline erosion and basement flooding predominate (between 19th and 38th Streets). 


\section{ADJUSTMENTS TO HAZARDS}

\section{Protection Measures}

Since all of the properties surveyed are privately owned, property owners have had to fend for themselves. Confronted with property hazards due to high lake levels, coastal flooding, and erosion, typical responses of property owners ranged from "doing nothing" (loss bearing) to installing a variety of structural devices for combating flood and erosion problems. Despite the seriousness of the hazards, only about one-third to one-half of the respondents reported some types of protection measures. The sump pump, used to protect against basement flooding, was the most popular flood-protection device; yet, only one-third of the respondents, on either side of the spit, used one (Table V). Only two respondents on each side had flood insurance on their properties. Many respondents suggested during personal interviews that the premium for the National Flood Insurance Program (NFIP) was too high. Others thought that the NFIP insurance was not available without the incorporation of a certain amount of flood-proofing in the original construction of the buildings.

A greater variety and number of structural measures were used for the protection of properties from erosion. Retaining walls (seawalls), riprap, and

Table V. Adjustments to Hazards

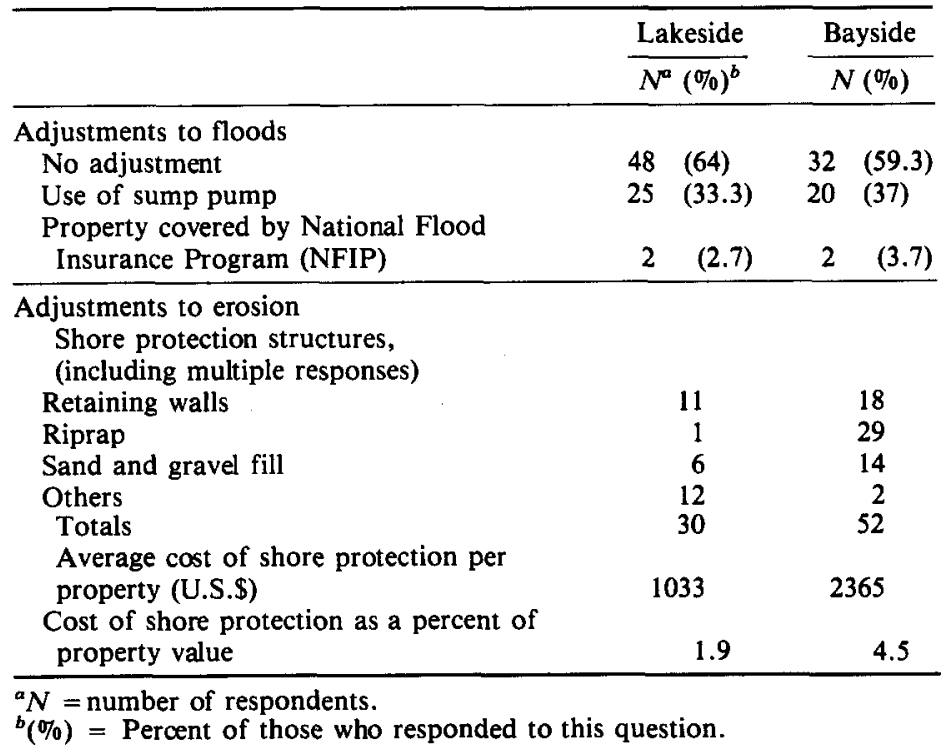


fill materials (sand and gravel) were the most favored measures. Not a single groin was reported from either side of the spit. Other measures mentioned included planting vegetation and building fences, particularly on the lakeside, for stabilizing and protecting dunes. The larger number of shore protection structures on the bayside indicate not only the higher density of low-lying coastal properties but also a longer life of structures in its lowenergy wave climate. Due to the severity of wave climate facing the lakeside, many of the coastal structures, in particular, wooden retaining walls and sand fences, are destroyed within a relatively short span of time unless they are constantly maintained and occasionally replaced. In general, most of the coastal structures on both sides of the spit are superficial in nature. This is reflected in the relatively small amount of investment made by individual property owners for shore protection measures $(1.9-4.5 \%$ of the property value, as reported in Table V).

\section{Responsibilities for Shore Protection}

One of the central issues related to property hazards on Minnesota Point is concerned with the justification for living so close to the edge of water. Living in a hazardous environment can be justified only if that environment is considered as a resource outweighing the risk (White, 1974). Probably most of the residents of Minnesota Point were attracted to the spit by the amenities of its shoreline. Erosion and flood damage on the shoreline should, therefore, be considered as an inherent operating cost of living in the coastal envrironment. To assess if property owners agreed with this proposition, they were asked "who should be responsible for shore protection measures?" Not only were they divided in their opinion, but more than one-half of them blamed the IJC and the Federal Government for raising the lake levels. That, in their opinion, was the primary cause of property hazards. More than threequarters of the respondents asserted that either the IJC alone or a combination of various levels of governments (Federal, State and Municipal) should be responsible for shore protection measures. Very few respondents (less than $8 \%$ ) agreed to bear full responsibilities, while less than $18 \%$ would settle for sharing responsibilities with the various levels of governments (Table VI, top). Because of the considerable contrasts in the nature of property hazards between the lakeside and the bayside, significant differences in the perception of hazard responsibilities were expected between the respondents of the opposite sides of the spit. The results of the survey do not support this expectation, as there was no significant lakeside-bayside dichotomy in respondents' assertions. Perhaps the common denominator of high levels and the perception that these levels were controlled principally by the IJC served as a pervasive theme throughout the entire spit. 
Table VI. Adjustment Policies

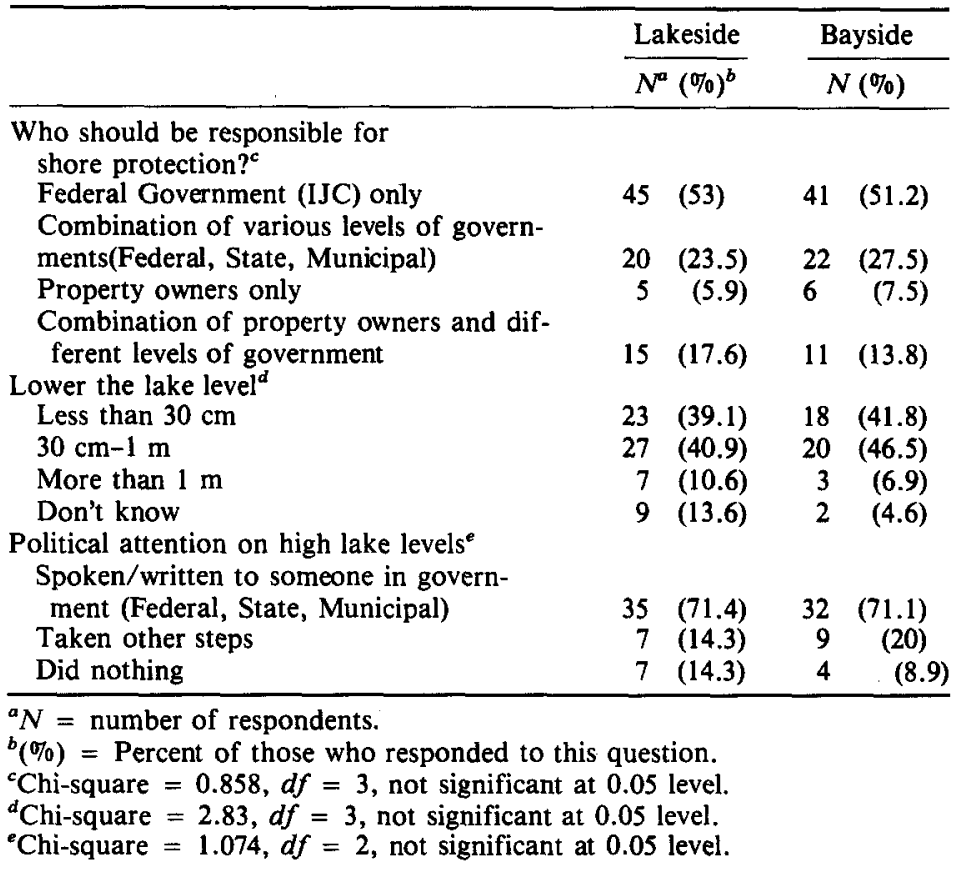

\section{Manipulating Lake Levels}

To test the hypothesis that the residents of Minnesota Point believed that the levels of Lake Superior were primarily dependent upon the IJC control, property owners were asked to give their opinion about the amount by which Lake Superior should be lowered from the 1985-1986 levels. Among those who responded to this question, only about $40 \%$ wanted to maintain the long-term normal level by lowering it less than $30 \mathrm{~cm}$; while more than $50 \%$ overestimated the need for lowering by suggesting amounts ranging between $30 \mathrm{~cm}$ and over $1 \mathrm{~m}$. Obviously, these respondents were not concerned about other Great Lakes interests, such as power production, shipping, boat launching, and marinas, that would be adversely affected by such lowering. Again, the pervasiveness of this theme is evident from the lack of any significant differences in responses between the lakeside and the bayside (Table VI, middle).

Technically, it is possible to further reduce fluctuations in Lake Superior levels by controlling the release of water from the Sault Ste. Marie locks and by manipulating the Ogoki-Long Lac diversions. However, the former would require expensive excavation of the outlet channels to increase 
their capacities when supplies are high, and the construction of control structures to reduce outflows when supplies are low (EC/OMNR, 1975). To supplement the effects of regulatory works at Sault Ste. Marie, the IJC recently investigated the potential of using the Ogoki-Long Lac diversion (inflows) as a means of regulating the levels of Lake Superior (IJC, 1988). An earlier investigation indicated that it would be possible to lower the levels of Lake Superior by only $10 \mathrm{~cm}$ over a period of 10 years, even if the entire inflow was shut off (Yee and Cuthbert, 1985). Such reductions would not be significant for the low-lying coasts of Minnesota Point, because the short-term oscillations of lake levels that accompany damaging storms exceed this range.

\section{Political Attention on High Lake Levels}

The residents of Minnesota Point cannot be blamed alone for their views on the role of the IJC. During the 1985-1986 high water period, various government agencies, including the State of Minnesota, St. Louis County, and the City of Duluth, made formal submissions to the U.S. House of Representatives (Subcommittee on Water Resources) implying that the IJC was responsible for the record high water levels in Lake Superior (Carson, 1987; Thorne, 1987). The main concern of these submissions centered around the IJC operation plan 1977, according to which Lake Superior was used as a storage reservoir to balance levels in other Great Lakes. It was pointed out that, prior to the adoption of this plan, Lake Superior was regulated according to its own level without reference to the lower lakes (Thorne, 1987). These views were well-publicized through the media, resulting in high degrees of awareness of the issue among the entire population of Minnesota Point. This might, in turn, have motivated property owners to press for further political action for lowering the lake levels, reinforcing the official position on this issue. To test this hypothesis, property owners were asked "what steps have you taken to bring the problem of high lake levels to the attention of politicians or government agencies?" Among those who responded to this question, a large number $(71 \%)$ had spoken or written to someone in the government on this issue. Other steps taken by about 14-20\% included attending community meetings on this issue or consultations with friends and neighbors. Again, there was no significant difference between the lakeside and the bayside in political attention on the issue of high lake levels (Table VI bottom).

\section{MANAGEMENT IMPLICATIONS}

It appears from the foregoing discussions that political attention has been focused on the wrong issue, i.e., on human-induced regulation of lake 
levels. In reality, the levels of Lake Superior and of other Great Lakes are primarily dependent upon climatic cycles. Existing regulatory structures on Lake Superior are capable of manipulating only small changes in levels. Significant manipulations would require major expansion of regulatory structures, the cost of which would outweigh the benefit derived from such installations. Since human ability to regulate lake levels is limited, greater attention should be given to measures that may be employed by governments to reduce hazard losses. Shoreline management represents such a measure for coping with the hazards of fluctuating lake levels.

The central philosophy of a comprehensive shoreline management plan is to protect existing development and to prevent future encroachment of high-risk reaches of the shoreline. On Minnesota Point, where a large number of coastal properties have already been developed, "shoreline management can guide decisions concerning effective and environmentally compatible shore protection methods" (Kreutzwiser, 1987). Most of the existing coastal structures on this spit, such as jetties and wooden retaining walls, were designed according to the normal lake levels without considerations for the impact of high lake levels. A comprehensive shoreline management plan would recognize that certain amounts of lake level fluctuations were inevitable, and therefore, a number of building codes would be incorporated into the original designs of coastal structures to cope with the effects of high lake levels. For example, buildings with flood-proofing and with setbacks, based on certain standards such as the 100-year lake level, might be aceptable for Minnesota Point where many low-lying properties are liable to flooding.

The main thrust of a shoreline management plan lies in its prevention component. Of all the prevention measures, perhaps the greatest potential for reducing shoreline damage lies in the implementation of land-use regulations. By prohibiting property development, local planning agencies can effectively control encroachment on hazard-prone reaches. Obversely, if permission is given to build on such reaches, these agencies cannot be absolved of their responsibilities. One of the objectives of the recently-formed Minnesota North Shore Management Board is to establish shoreline management standards, which would be used for monitoring future encroachment of all coastal areas in Minnesota, including those of Minnesota Point.

\section{CONCLUSION}

This study examined a number of hypotheses related to the recent (1985-1986) high water levels in Lake Superior and the resulting property hazards along the shorelines of Minnesota Point, Duluth. The study confirmed the central hypothesis that the majority of the residents of Minneso- 
ta Point perceived human regulation systems, i.e., the regulation of lake levels by the IJC, to be the main cause of high lake levels and shore property hazards. An alternative hypothesis, that the perception of the causes of property hazards as well as the attitude toward the responsibility for shore protection measures were conditioned by the nature of property hazards experienced by individual property owners, was rejected by the results of the questionnaire survey. Despite significant differences in property setting and the nature of hazards between the lakeside and the bayside of the spit, the study indicated that there was no significant relationship between the location of properties and the respondents' perception of the underlying causes of their property hazards.

To cope with flood and erosion hazards, many property owners have made use of a range of protection measures, but most of them perceived lower lake levels as a higher priority than providing shore protection measures. Such a perception implied that lake levels were primarily dependent upon human regulation systems. Consequently, very few respondents would like to bear full responsibility for shore protection measures, despite the fact that they had made the choice to live on the hazardous edge of water. The most direct evidence in support of the central hypothesis was provided by the political attention on high lake levels. During the 1985-1986 high water period property owners as well as their political representatives started lobbying the Federal Government to apply pressure on the IJC to lower lake levels. In most of these political submissions, a number of IJC flow regulation plans were critized without analysis of the physical constraints of these plans. The present study reviewed the physical limitations of controlling water levels and recommended that a more productive approach would be to focus political attention on shoreline management, which could provide sound guidelines for protecting existing properties and for preventing future encroachment on the remaining unused reaches of the shorelines of Minnesota Point.

\section{ACKNOWLEDGMENTS}

This study was financed by a Lakehead University/University of Minnesota-Duluth (UMD) co-operative research project. Dale Baker, Director of the Minnesota Sea Grant Extension Program, UMD, provided useful support services for the mail questionnaire survey. The authors are indebted to two anonymous referees for their constructive criticisms and suggestions. Sincere thanks are also due to Robert S. Dilley and David D. Kemp for their helpful comments on the manuscript. The diagrams were drafted by Greg Pitkanen. 


\section{REFERENCES}

Carson, J. H. (1987). Regulation of high water levels of Lake Superior. Subcommittee of Water Resources, U.S. House of Representatives, Duluth, Minnesota, March 17, 1987.

Clawson, M. (1972). Social needs and the urban-marine environment. In Brahtz, J. F. P. (ed.), Coastal Zone Management: Multiple Use With Conservation. John Wiley \& Sons, New York.

CORPS OF ENGINEERS (COE) (1976). Great Lakes Shoreline Damage Survey: Saint Louis County, Minnesota. U.S. Army Corps of Engineers North Central Division Report, Chicago.

ENVIRONMENT CANADA AND ONTARIO MINISTRY OF NATURAL RESOURCES (EC/OMNR) (1975). Canada/Ontario Great Lakes Shore Damage Survey. Technical Report, Environment Canada, Ottawa.

Hough, J. L. (1958). Geology of the Great Lakes. University of Illinois Press, Urbana.

INTERNATIONAL JOINT COMMISSION (IJC) (1988). Interim report on 1985-86 high water levels in the Great Lakes-St. Lawrence River Basin. IJC, Ottawa, October 1988.

Kreutzwiser, R. D. (1987). Managing the Great Lakes shoreline hazard. Journal of Soil and Water Conservation 42 (3): 150-154.

Loy, W. G. (1963). The formation of the Duluth-Superior Harbor. The Minnesota Academy of Science Proceedings 31(1): 28-35.

Quinn, F. H. (1987). Lake Hydrology Group, Great Lakes Environmental Resarch Laboratory Subcommittee of Water Resources, U.S. House of Representatives, March 1987.

Resio, D. T., and Vincent, C. L. (1978). Design Wave Information for the Great Lakes; Report 5, Lake Superior. U.S. Army Engineers Waterways Experiment Station Technical Report H-76-1, Vicksuburg.

Rowntree, R. A. (1974). Coastal erosion: The meaning of a natural hazard in the cultural and ecological context. In White, G. F. (ed.), Natural Hazards: Local, National, Global. Oxford University Press, New York.

Thorne, S. G. (1987). Regulation of high water levels of Lake Superior. Subcommittee of Water Resources, U.S. House of Representatives, March 1987.

White, G. F. (ed.) (1974). Natural Hazards: Local, National and Global. Oxford University Press, Toronto.

Yee, P., and Cuthbert, D. (1985). A report on the 1985 record high water levels of the Great Lakes. Inland Waters Directorate-Ontario Region, Water Planning and Management Branch, Environment Canada. 